\title{
LARGE DIAMETER 718 INGOTS FOR LAND-BASED GAS TURBINES
}

\author{
S. V. Thamboo*, R. C. Schwant*, L. Yang* \\ L. A. Jackman, B. J. Bond, R. L. Kennedy \\ *General Electric Power Systems \\ One River Road \\ Schenectady, NY 12345 \\ Allvac, an Allegheny Technologies Company \\ 2020 Ashcraft Avenue \\ Monroe, North Carolina 28110
}

\begin{abstract}
New high efficiency land based gas turbines made by General Electric Company have a significantly higher firing temperature than previous units. These new units require alloy 718 for turbine rotor disks which are many times heavier than aircraft engine size disks. Producing large diameter ingots for such components presents unique melting challenges. This paper discusses the development of these melting processes and presents results from ingots and forgings. Production parts are being produced from ingots $685 \mathrm{~mm}$ in diameter. Ingots up to $915 \mathrm{~mm}$ diameter have been produced and are in the process of being forged into parts for evaluation.
\end{abstract}

Superalloys 718.625 .706 and Various Derivatives

Edited by E.A. Loria

TMS (The Wincrals. Wetals \& Materials Society), 2001

57 


\section{Introduction}

Materials used for turbine rotors in land-based gas turbines have typically been CrMoV steels. However, the need for better efficiency has required higher firing temperatures that in turn requires higher temperature capability than steels can provide. Cooling the rotor disks is one way to stay within the temperature capability of traditional steels. However, this has a negative impact on efficiency of the unit. General Electric company chose an alternate more efficient approach during the design of their F class turbines in the late 80's ${ }^{(1)}$. Alloy 706, which has higher material temperature capability, was selected for turbine wheels in turbines firing at temperatures up to $2450^{\circ} \mathrm{F}$. This was a big step because the large size ingots needed for these components had never been made before and there were serious concerns regarding segregation. Fortunately, a successful VIM-ESR-VAR triple melting technology was developed and over 1000 disks have been produced. However, GE's new FB and $\mathrm{H}$ machines now employ even higher firing temperatures than the F class machines to achieve even better turbine efficiency. These temperatures exceed the capability of alloy 706; therefore, alloy 718 has been chosen for the turbine wheels. The 718 turbine rotor is shown on its half shell in an $\mathrm{H}$ class machine in Figure 1.

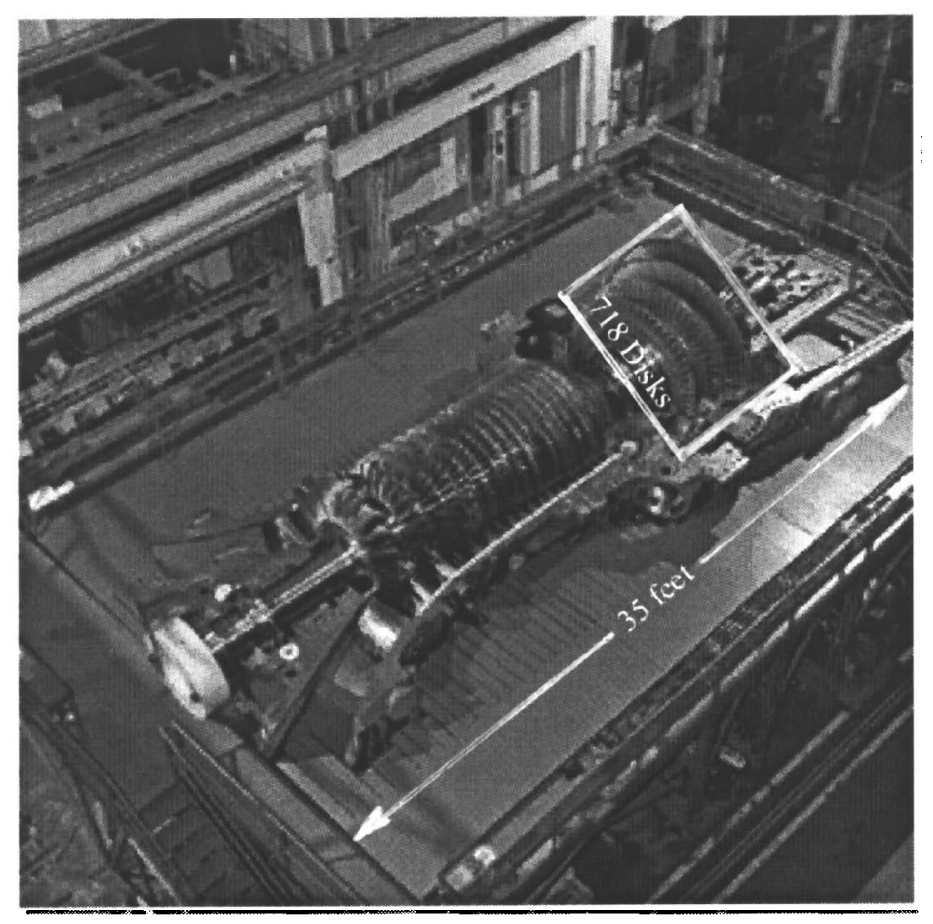

Figure 1. Half-shell view of H turbine rotor

Alloy 718 has been used extensively in aircraft engines for several decades. It has been the alloy of choice for turbine disks because of excellent strength and LCF properties from room temperature to over $600^{\circ} \mathrm{C}$. Melting and forging processes have been developed and perfected over the years. However, transitioning this technology to land-based gas turbines is not straightforward because of the size of the components. Typical aircraft engine parts range from $200-1000 \mathrm{~kg}$ and can be made from ingots of approximately $500 \mathrm{~mm}$ diameter. Land-based gas turbine disks are $6000-15,000 \mathrm{~kg}$. GE heavy-duty gas turbines require ingots that are $685 \mathrm{~mm}$ to $915 \mathrm{~mm}$ in diameter. The large diameter of the ingot increases the likelihood for melt-related defects $^{(2)}$. Each ingot also makes only one part; therefore, any melt-related defect would result in scrapping the entire ingot. Because of these considerations, careful attention must be paid to the melt processing of these large ingots. 


\section{Melting Technology Development}

\section{Background}

In the mid 80's, GE began to specify triple melting (VIM+ESR+VAR) for critical rotating components produced from 718 for aircraft applications. The triple melt process consists of primary melting by vacuum induction (VIM) plus an intermediate step of electroslag melting (ESR) followed by vacuum arc remelting (VAR) to produce the final ingot size. The intermediate ESR process yields a sound electrode for the final VAR step. The absence of cracks and large shrinkage cavities produces a more stable remelt operation, reducing the occurrence for melt anomalies and eliminating fall-in of dendrite tips or other pieces of the electrode which cause dendritic white spots ${ }^{(8)}$. The ESR step also improves microcleanliness by removing oxide inclusions, which minimizes oxide-nitride stringers in the final product. It has been documented ${ }^{(3)}$ that triple melted alloy 718 exhibits more than an order of magnitude fewer ultrasonic indications relative to double melted material for $508 \mathrm{~mm}$ diameter billet. Prior to recent developments, it was long felt that 718 could not be made in ingot sizes larger than 508 $\mathrm{mm}^{(2)}$. However, success with triple melted ingots of 706 up to diameters of $1000 \mathrm{~mm}$ showed that perhaps larger ingots were possible for triple melted 718 also. Hence, an effort was started to make a $685 \mathrm{~mm}$ diameter ingot.

\section{Chemistry}

The chemistry for standard premium quality alloy 718 was altered slightly for $685 \mathrm{~mm}$ diameter ingots. Niobium was slightly reduced because it has a strong segregation tendency during solidification $^{(4)}$. Carbon was lowered to minimize carbides and freckles formation. The lower carbon also increases the amount of niobium available for strengthening as $\gamma^{\prime \prime}$ because less niobium will be tied up as carbides ${ }^{(5,6)}$. Also, reduced carbon results in improved carbide distributions that can favorably influence mechanical properties such as low cycle fatigue. In addition, silicon was lowered to minimize the stability of Laves phase ${ }^{(1)}$. Table I provides a typical analysis.

Table I. Typical Composition, Weight \%

\begin{tabular}{|c|c|c|c|c|c|c|c|c|c|}
\hline $\mathrm{C}$ & $\mathrm{Cr}$ & $\mathrm{Mo}$ & $\mathrm{Nb}$ & $\mathrm{Ti}$ & $\mathrm{Al}$ & $\mathrm{Si}$ & $\mathrm{Fe}$ & $\mathrm{B}$ & $\mathrm{Ni}$ \\
\hline 0.01 & 17.9 & 3.02 & 5.03 & 0.9 & 0.44 & 0.01 & 18.2 & 0.003 & Balance \\
\hline
\end{tabular}

\section{Modeling}

Computer modeling of the remelting processes and all of the thermal cycles applied to large 718 ingots during manufacturing has proven very valuable. Before work began on the $685 \mathrm{~mm} 718$ ingots, the largest, commercially available ingot of "rotor quality" 718 , i.e. free of both positive and negative segregation, was $610 \mathrm{~mm}$ diameter. To guide the initial VAR melt development program, a series of trials were conducted using VAR model BAR v4-3. This model was developed by Sandia National Laboratory under the direction of the SMPC (Specialty Metals Processing Consortium). Figure 2 shows a comparison of results predicted by the model to actual pool profiles for a $685 \mathrm{~mm}$ diameter ingot. While the state of VAR model development is not yet to the level that would allow prediction of segregation, knowledge of the size and shape of pools which produce good results allow a first approximation of acceptable melting conditions. 
The VAR model also provides parameters such as local solidification time. Figure 3 demonstrates how localized solidification time increases with increasing ingot diameter. Results are normalized to an ingot diameter of $508 \mathrm{~mm}$.

An in-house code for simulation of thermal transients in ingots and billets for modeling of heating and cooling cycles was used to develop thermal cycles for specific furnaces and loading conditions. While the model does not predict stresses, it was used to optimize thermal treatments by minimizing temperature gradients.

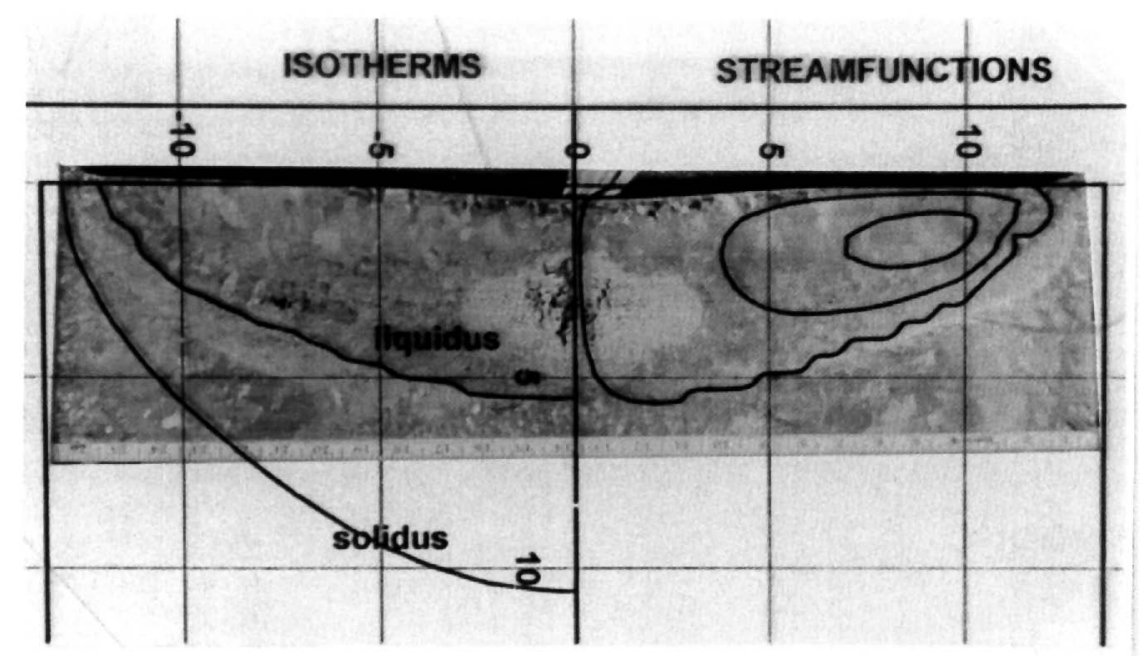

Figure 2. Calculated liquidus and solidus isotherms and fluid streamlines superimposed on the actual pool for a $685 \mathrm{~mm}$ diameter VAR ingot of 718 .

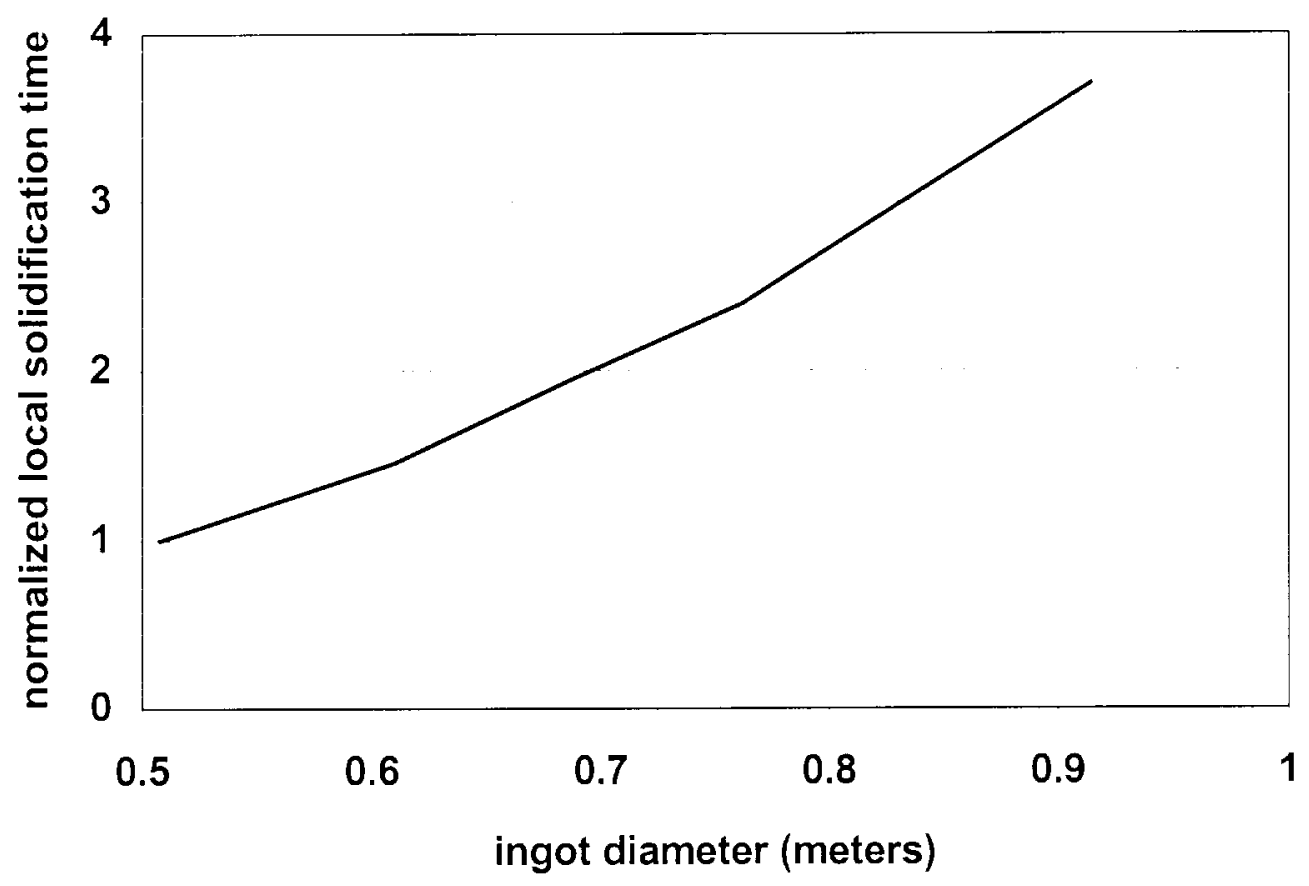

Figure 3. Local solidification time as a function of ingot diameter for alloy 718 as calculated with the VAR model. 
Overview - When the decision was made several years ago to evaluate the possibility of producing acceptable alloy 718 ingots $685 \mathrm{~mm}$ in diameter, a series of trial ingots were melted $^{(7)}$. These were forged to billet between 254 and $355 \mathrm{~mm}$ in diameter for evaluation since macrosegregation such as freckles and white spots is more readily detected in wrought billet structures than in the as-cast condition. Also, wrought billet structures can be ultrasonically inspected because of the finer grain size. The top ends of selected ingots were removed in the as-cast condition prior to forging and then sectioned to view the VAR pool profile. Melting parameters were varied in these trial ingots to establish control limits and to optimize the process.

Similar trials have recently been conducted each time a need occurred for even larger diameter ingots of alloy 718. Data from trial ingots have now been generated for ingots 760,835 , and $915 \mathrm{~mm}$ in diameter. The following discussion will focus on the $915 \mathrm{~mm}$ diameter ingots.

Melt Pool and Ingot Macrostructure - A longitudinal section from the top of a $915 \mathrm{~mm}$ diameter trial ingot is shown in Figure 4. The pool profile was marked by magnetic stirring for 20 minutes during steady state melting followed by an immediate power shut off. Pool depth is relatively shallow at about $90 \mathrm{~mm}$. A typical transverse ingot structure is presented in Figure 5 which represents the bottom surface of the section in Figure 4. No indication of macrosegregation is evident.

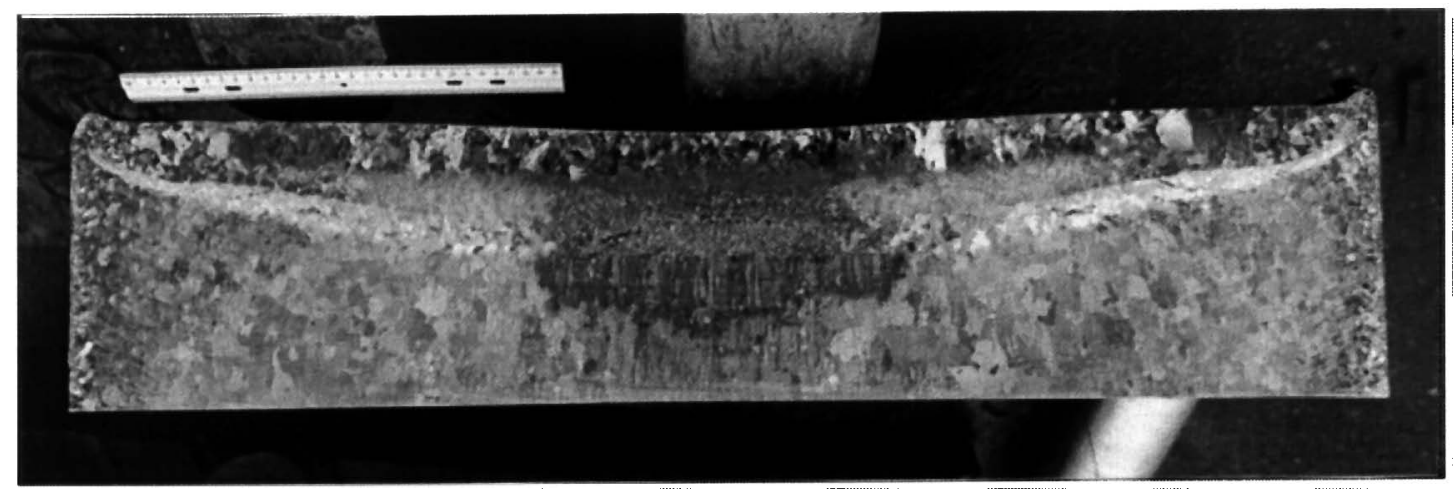

Figure 4. Pool profile for $915 \mathrm{~mm}$ diameter ingot.

Billet Macrostructure - Etched plates were examined at several locations for each set of melt parameters with each plate representing the full billet cross section. Also, etched plates were taken at all ultrasonic indications. A typical macrostructure of $254 \mathrm{~mm}$ diameter billet from an ingot $915 \mathrm{~mm}$ in diameter is shown in Figure 6. It has a uniform structure with no evidence of positive segregation. A few small solidification white spots are evident near the surface. Such solidification white spots are clean (not associated with carbides, carbonitrides, or other inclusions) and are not detrimental to mechanical properties ${ }^{(8)}$. Figure 7 shows a typical solidification white spot in billet from a $760 \mathrm{~mm}$ diameter ingot. The "half moon" appearance is common but solidification white spots exhibit numerous shapes. Chemistry differences between matrix and white spots for $915 \mathrm{~mm}$ diameter ingots are minor and similar to those for smaller diameter ingots. This is illustrated in Figure 8 which provides average chemistries for six solidification white spots in billets from an ingot $915 \mathrm{~mm}$ in diameter. 


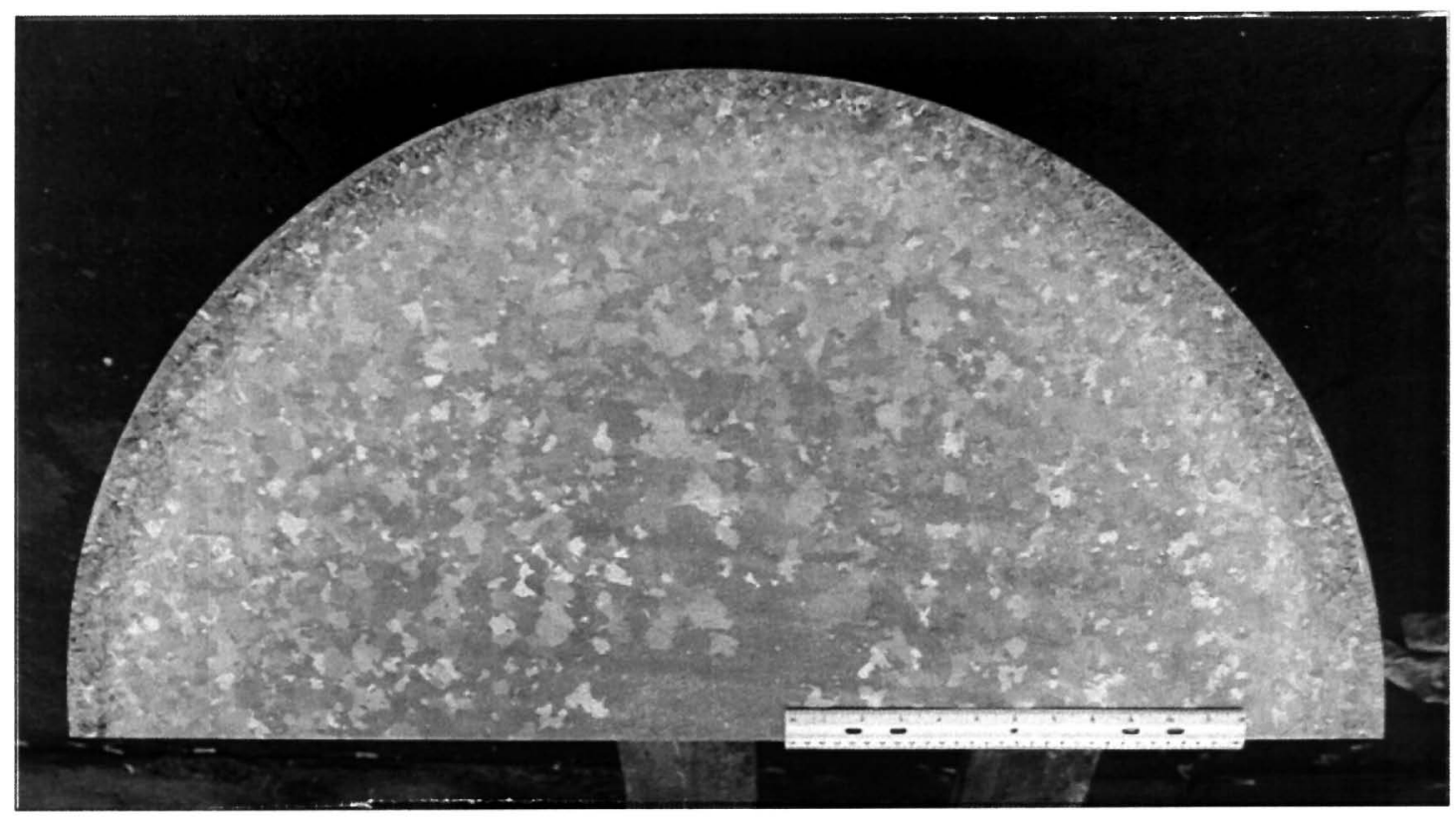

Figure 5. Transverse macrostructure of the bottom ingot section in Figure 4.

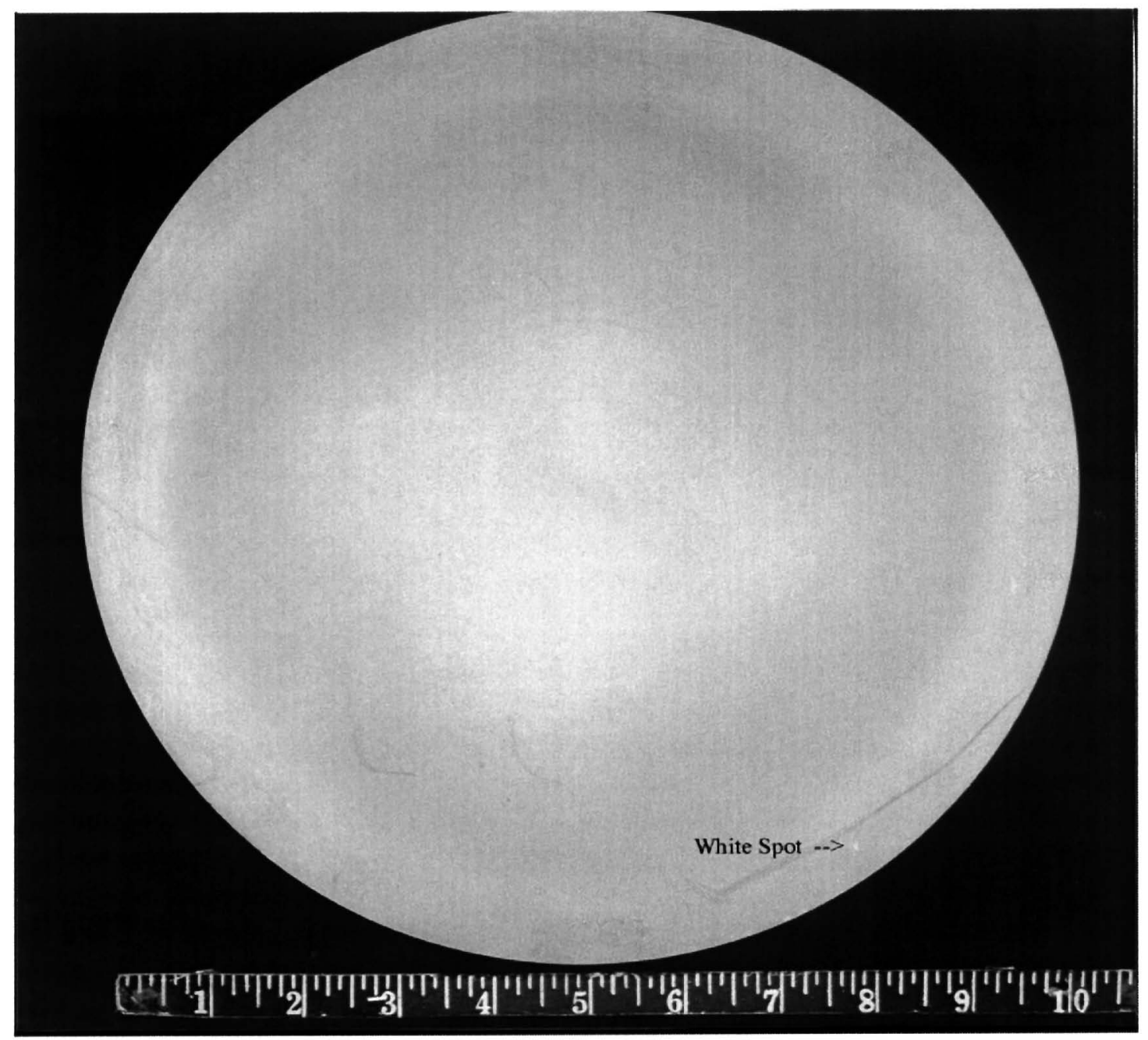

Figure 6. Typical microstructure of $254 \mathrm{~mm}$ billet from a $915 \mathrm{~mm}$ diameter ingot. A small solidification white spot is marked. 


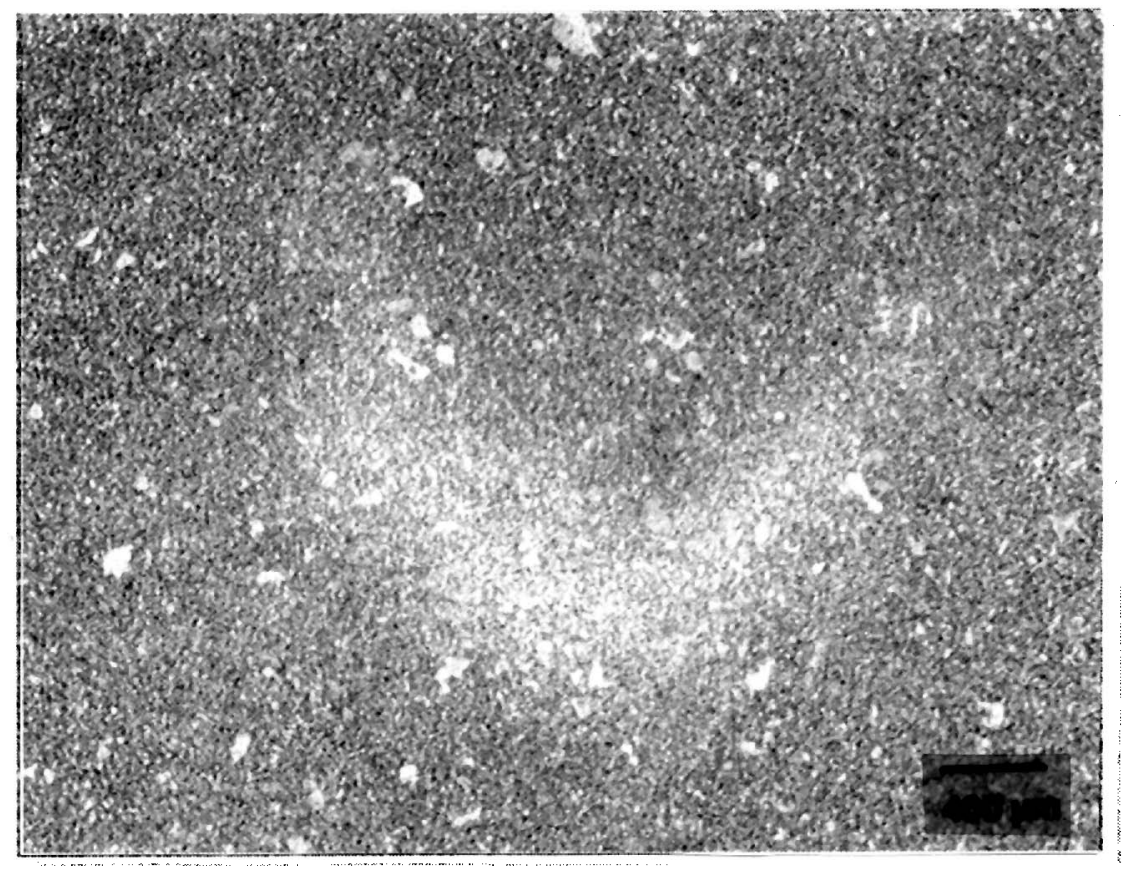

Figure 7. Solidification white spot in billet from a $760 \mathrm{~mm}$ diameter ingot.

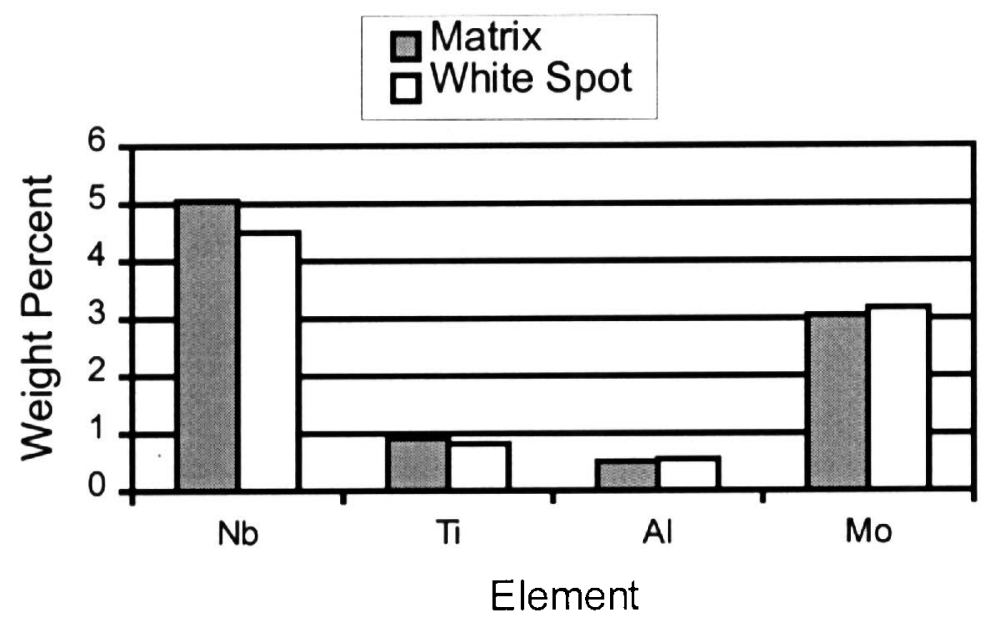

Figure 8. Average chemistry difference between solidification white spots and matrix for an ingot $915 \mathrm{~mm}$ in diameter.

Billet Microstructure - Etched microstructures are similar to those for billets from smaller diameter ingots. Typical microstructures at mid-radius and center locations are presented in Figure 9 for billet $254 \mathrm{~mm}$ in diameter from a $915 \mathrm{~mm}$ diameter ingot. No significant differences for carbide and carbonitride distributions have been observed with ingot diameters in the range of 508 to $915 \mathrm{~mm}$. The lower carbon level for larger diameter ingots results in more favorable distributions relative to the standard carbon levels typical of $508 \mathrm{~mm}$ diameter ingots for aerospace applications. This is apparent in Figure 10 and 11 which show carbide and carbonitride distributions for typical and worst fields, respectively. Both figures show distribution for ingots 508, 685, and $915 \mathrm{~mm}$ in diameter. Standard and low carbon results are shown for $685 \mathrm{~mm}$. An attempt was made to evaluate individual carbide, nitride, and carbonitride particle size as a function of ingot diameter. However, the scatter requires numerous measurements and results available at this time are not sufficient to be statistically meaningful; additional measurements are underway. 


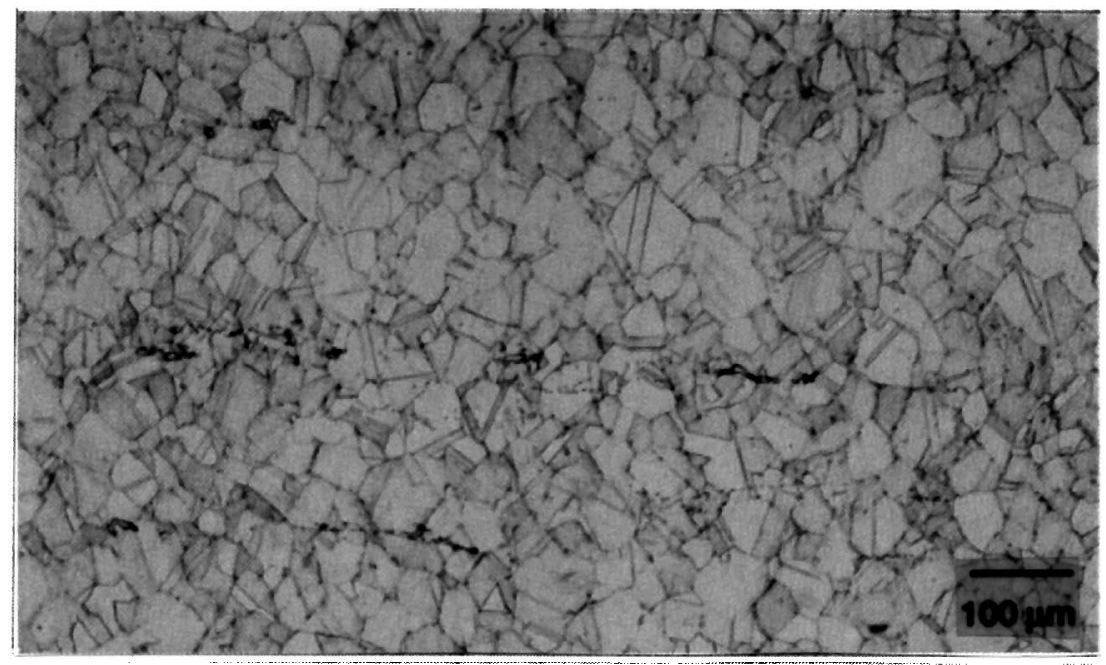

Center

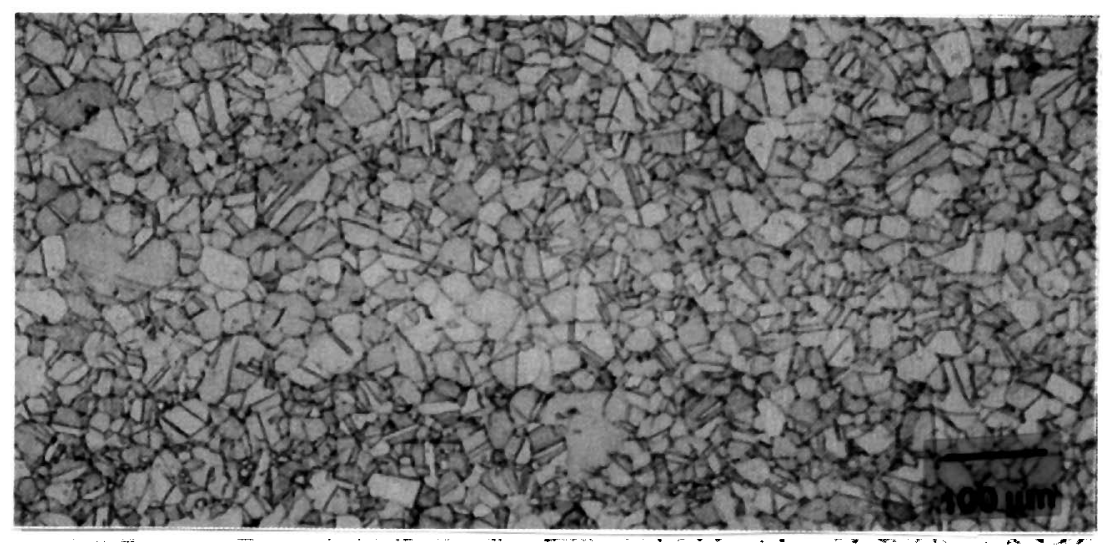

Mid-radius

Figure 9. Typical microstructure for $254 \mathrm{~mm}$ diameter billet made from a $915 \mathrm{~mm}$ diameter ingot.

Process Control - Careful process control is required for each melting operation using the control limits established from the trial ingots. Special emphasis is required on the final melt process where several melt parameters must be carefully controlled. It is not sufficient to concentrate only on the steady state portions of the final melt process; start-up and hot topping procedures must also be considered. One of the final melt parameters for which the process window must be well defined and controlled is melt rate. When the melt rate extends below the bottom limit, numerous solidification white spots appear. Positive segregation occurs when the melt rate becomes too high. Freckles appear when the positive segregation is severe. Freckles in alloy 718 contain Laves phase in addition to extensive delta phase and high densities of carbides and carbonitrides. However, the first indications of positive segregations are not true freckles but interdendritic regions enriched in niobium that appear as bands. An example is provided in Figure 12 where it is shown both optically and by SEM. This example was triggered by an intentional melt interruption during VAR of an ingot $915 \mathrm{~mm}$ in diameter. These bands usually can be detected with careful inspection of transverse macroplates where they appear as dark etching specks.

Thermal Treatments - Trial ingots also provided an opportunity to evaluate practices for heating and cooling electrodes and ingots during various operations of ingot melting. As ingot diameter increases, more conservative thermal practices are needed to avoid thermal cracking because heat extraction from the ingot interior becomes more difficult. Consequently, more severe thermal gradients are generated and larger residual stresses prevail. Figure 13 illustrates this 


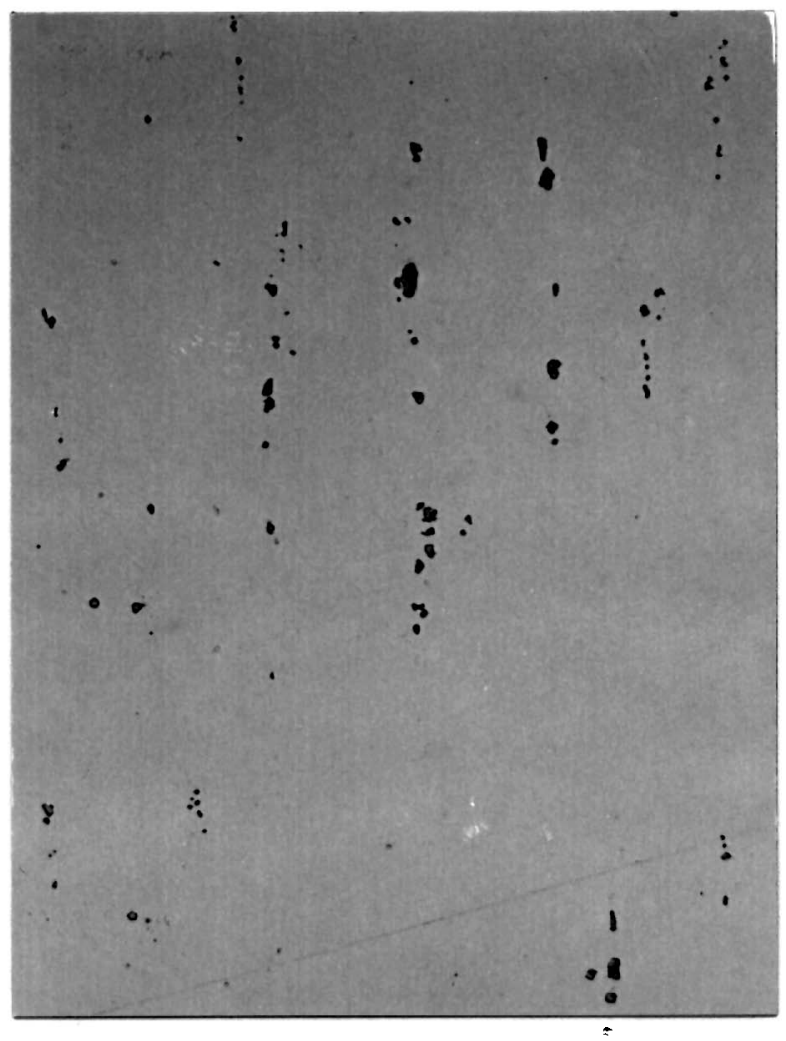

$254 \mathrm{~mm}$ billet from $508 \mathrm{~mm}$ ingot Carbon $=0.024 \%$

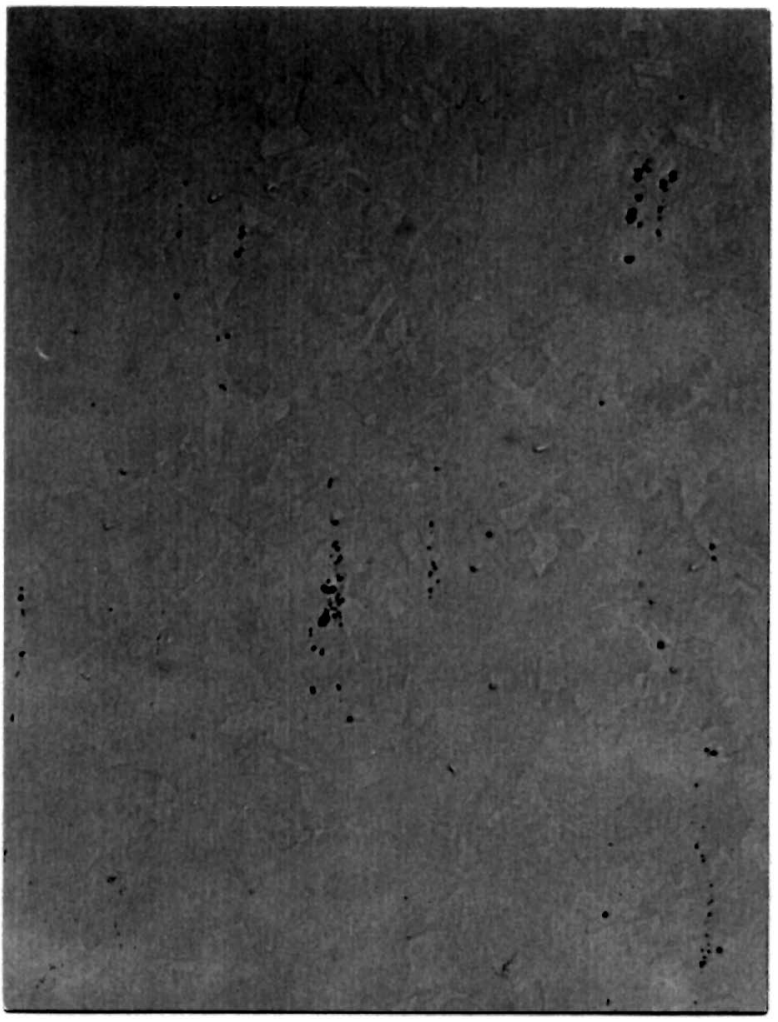

$355 \mathrm{~mm}$ billet from $685 \mathrm{~mm}$ ingot Carbon $=0.011 \%$

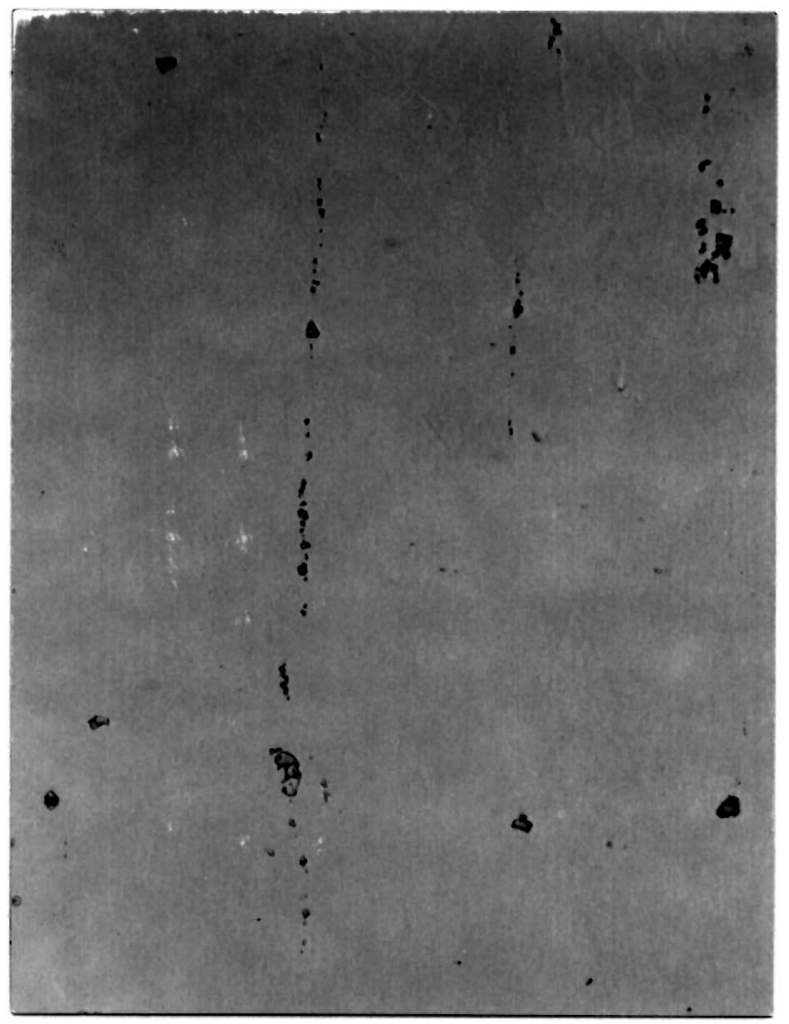

$355 \mathrm{~mm}$ billet from $685 \mathrm{~mm}$ ingot Carbon $=0.027 \%$

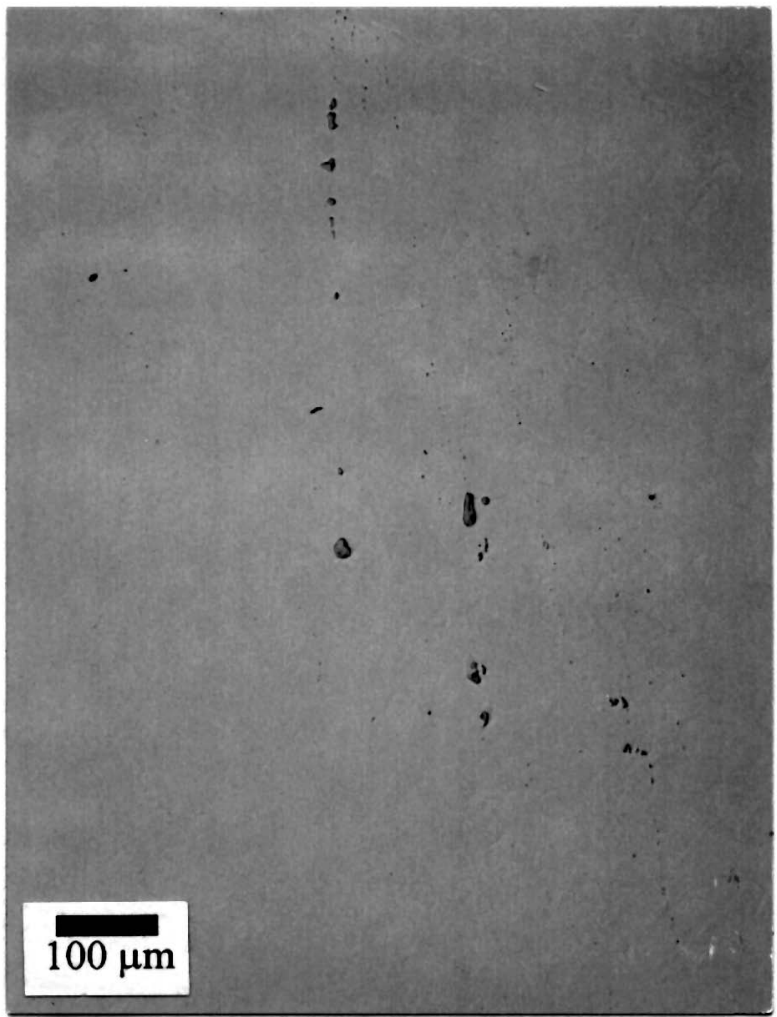

$254 \mathrm{~mm}$ billet from $915 \mathrm{~mm}$ ingot Carbon $=0.010 \%$

Figure 10. Typical carbonitride fields. Longitudinal center micros from selected combinations of ingot diameter, billet diameter, and carbon content for VIM-ESR-VAR alloy 718. 


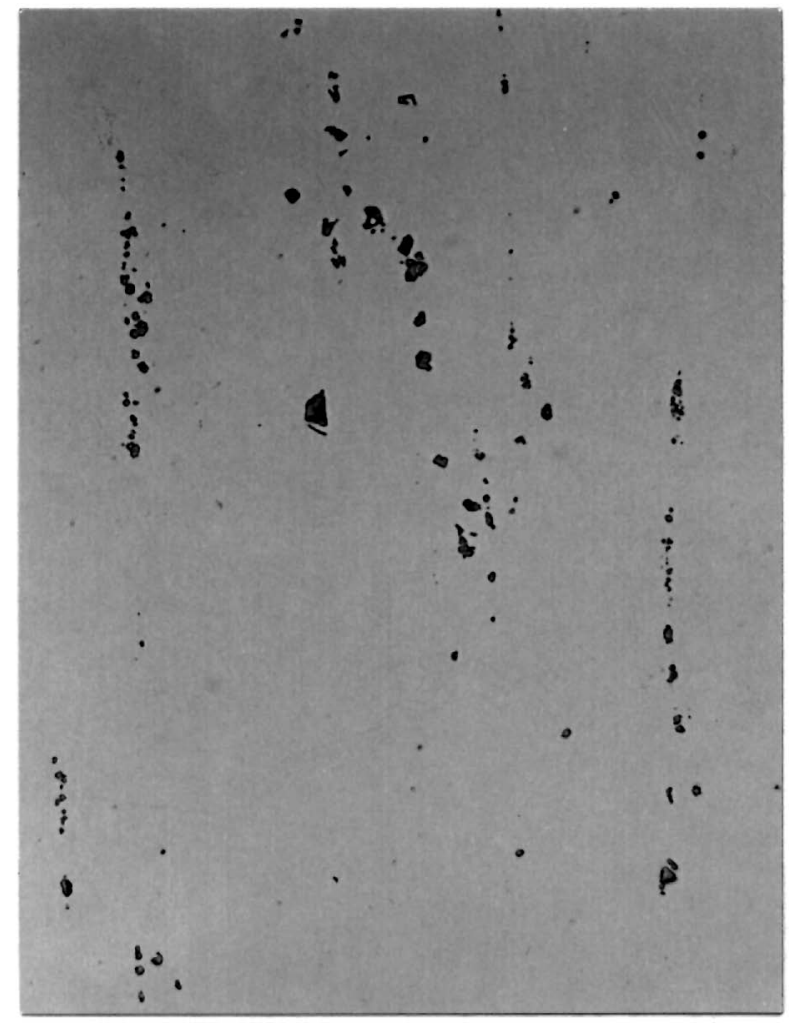

$254 \mathrm{~mm}$ billet from $508 \mathrm{~mm}$ ingot Carbon $=0.024 \%$

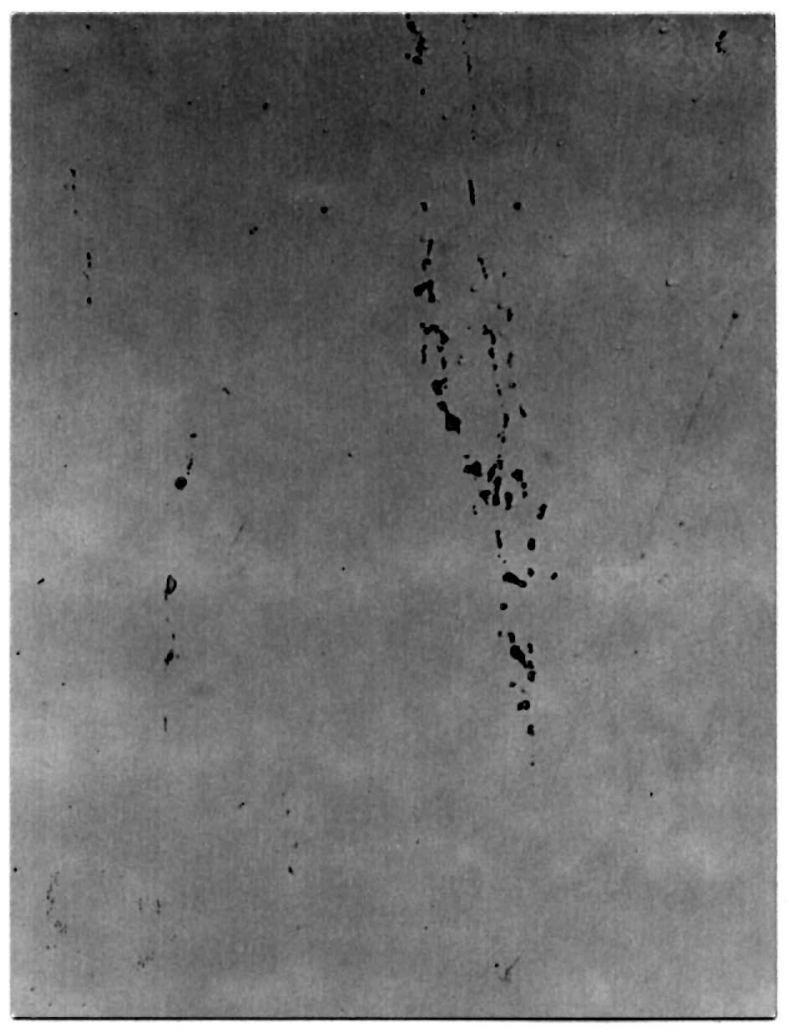

$355 \mathrm{~mm}$ billet from $685 \mathrm{~mm}$ ingot Carbon $=0.011 \% \mathrm{~m}$

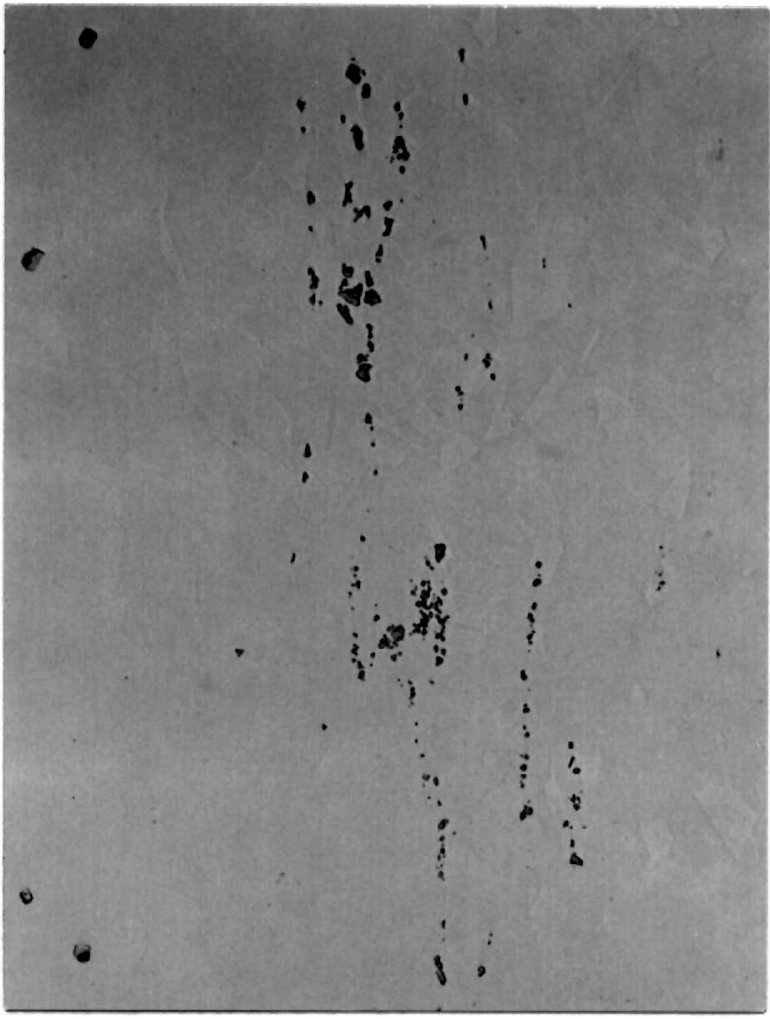

$355 \mathrm{~mm}$ billet from $685 \mathrm{~mm}$ ingot Carbon $=0.027 \%$

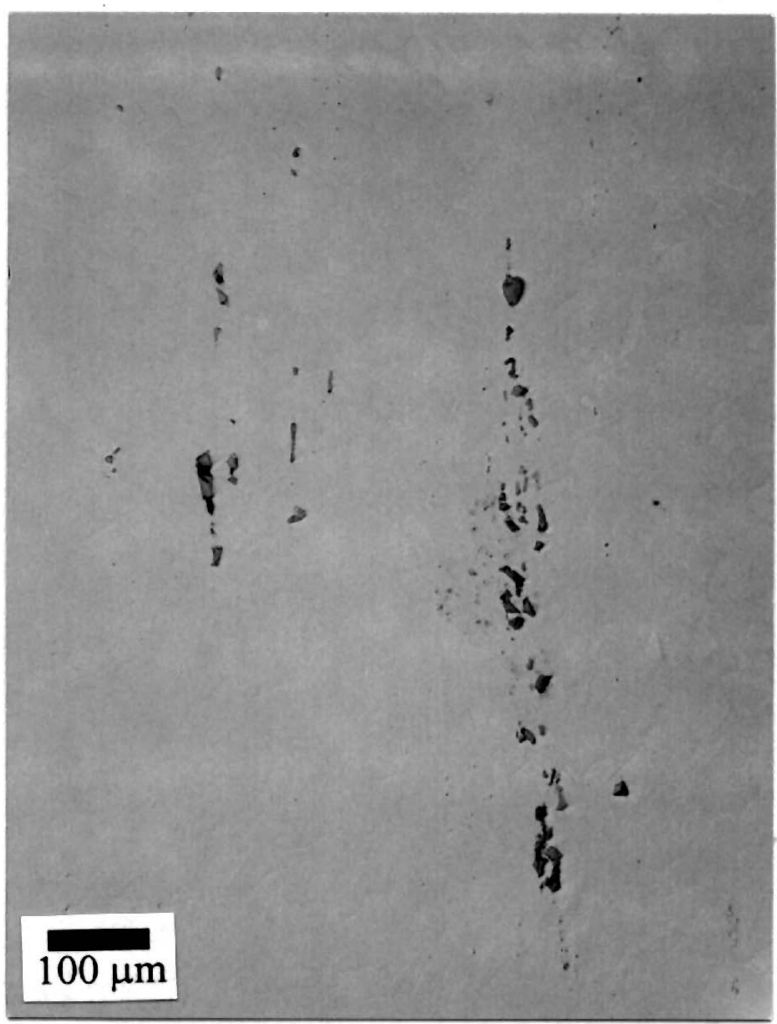

$254 \mathrm{~mm}$ billet from $915 \mathrm{~mm}$ ingot Carbon $=0.010 \%$

Figure 11. Worst carbonitride fields. Longitudinal center micros from selected combinations of ingot diameter, billet diameter, and carbon content for VIM-ESR-VAR alloy 718 . 


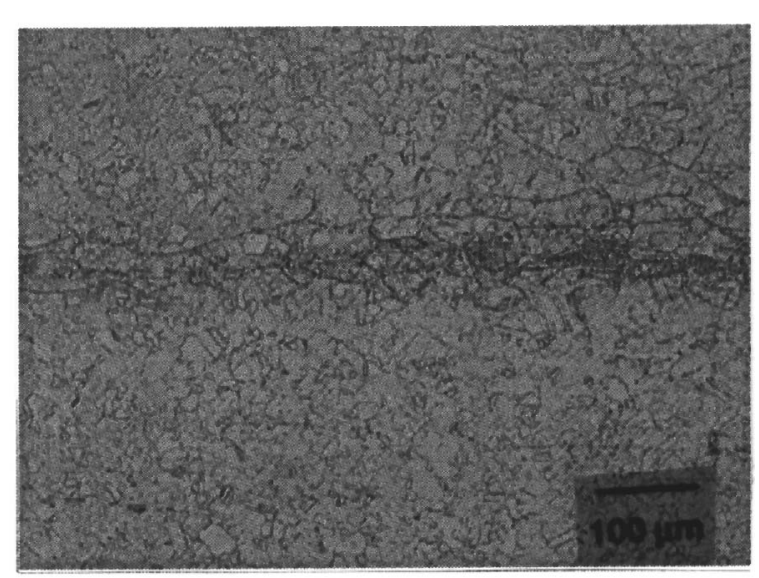

Optical

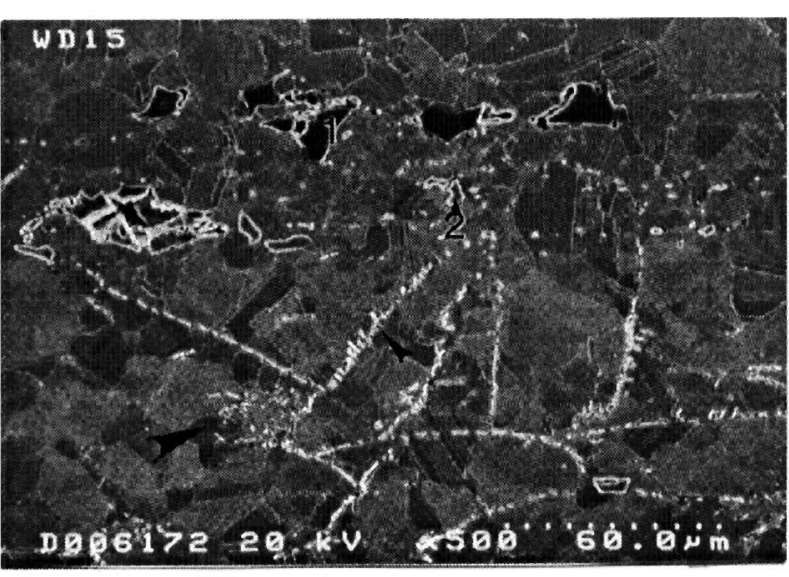

SEM

Figure 12. Longitudinal band of positive segregation in $254 \mathrm{~mm}$ diameter billet caused by an intentional melt interruption.

effect by comparing the calculated surface to center temperature differential for a $915 \mathrm{~mm}$ diameter ingot versus that for an ingot $508 \mathrm{~mm}$ in diameter when charged into a furnace operating at $1090^{\circ} \mathrm{C}$. When heating and/or cooling is too aggressive, catastrophic cracking can occur such as that shown for a large alloy 718 ingot in Figure 14. The potential for thermal cracking is also higher in as-cast structures because of relatively low ductility due to microsegregation. This is especially true for alloy 718 where Laves phase is present at interdendritic regions.

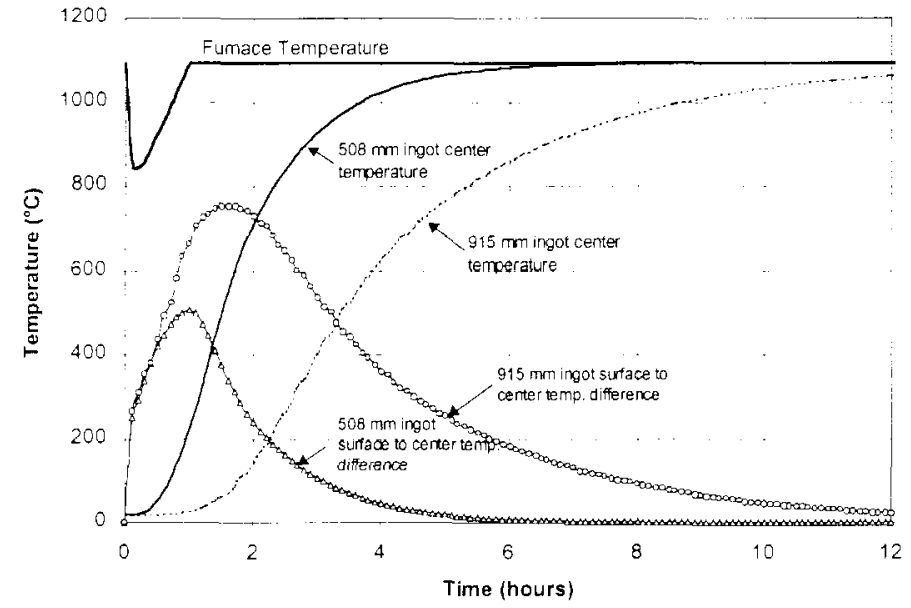

Figure 13. Heating profiles for $508 \mathrm{~mm}$ and $915 \mathrm{~mm}$ diameter 718 ingots direct loaded into a $1090^{\circ} \mathrm{C}$ furnace.

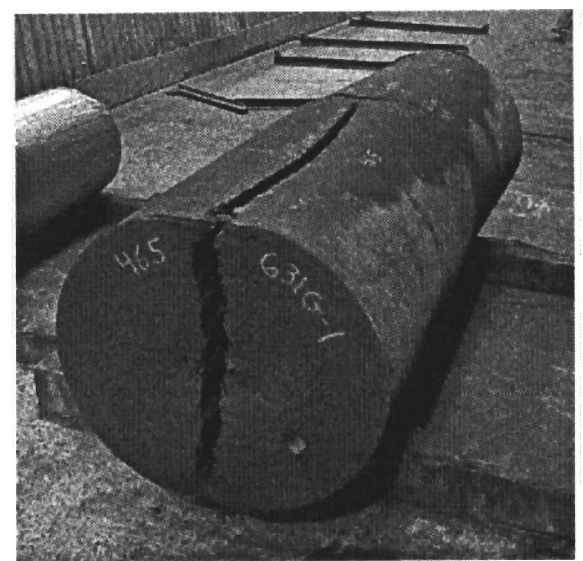

Figure 14. Thermal cracks in large diameter alloy 718 ingot processed with a thermal cycle that was too aggressive.

\section{Product Evaluation}

Melting process development began on $685 \mathrm{~mm}$ ingots in the mid $90^{\prime} \mathrm{s}^{(7)}$. Details of the development and qualification efforts were discussed at the 1997 Superalloys Conference. The process is now fully qualified and over 30 parts have been made. The results have been very good. 


\section{U1trasonic Testing}

Unlike billet for aircraft engine parts, the large diameter billet made from these ingots for production parts has a relatively coarse grain structure and cannot be inspected to the required levels by UT. Inspection is only done after the part is forged and heat-treated. An automated inspection system with separate longitudinal wave and shear wave tests is used to interrogate different orientations for defects. Since the melt process has been fully developed and optimized, there have been no failures due to the presence of melt-related defects or inclusions.

\section{Mechanical Properties and Structures}

All forgings are tested for tensile, LCF and $\mathrm{J}_{\mathrm{Ic}}$. The $0.2 \%$ yield strengths for these large forgings are somewhat lower than the aircraft engine size forgings. This is because the cooling rate obtained in such large forgings is much slower than for smaller aircraft engine parts. A study on the effect of cooling rate showed that this cooling rate had a bigger effect than the lower niobium content of $5.0 \mathrm{wt} \%$ compared to $5.5 \mathrm{wt} \%$. Figure 15 shows the effect of cooling rate on yield strength for both the high niobium and the low niobium 718 .

There is essentially no difference in the UTS for both the low niobium and standard niobium 718 at both slow and high cooling rates from solution temperature.

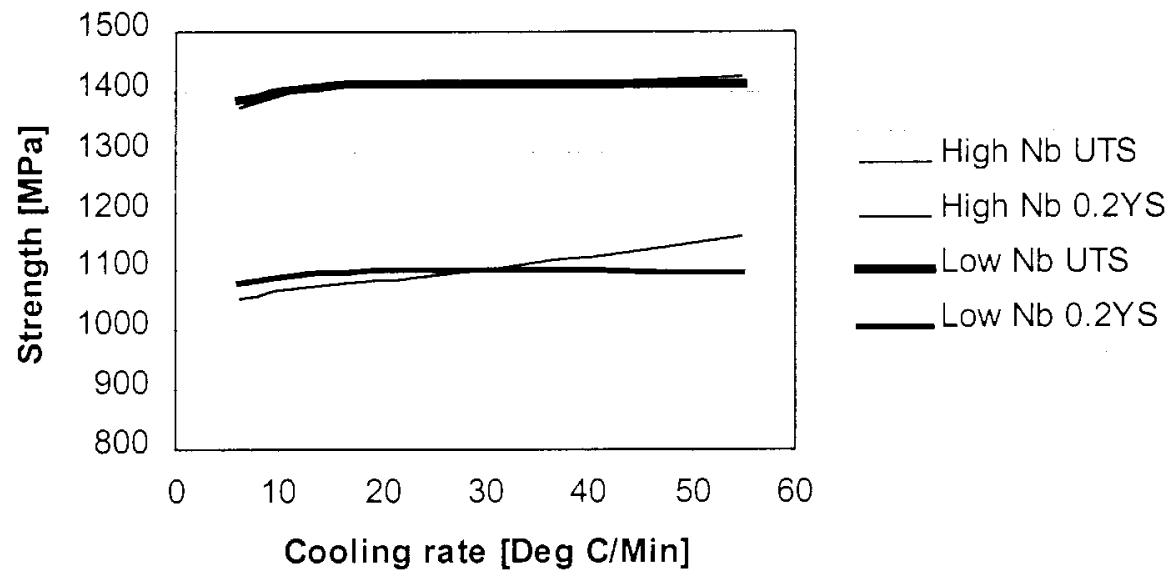

Figure 15. Effect of cooling rate on UTS and yield strength for high and low niobium grades of alloy 718 .

However, it can be seen that at high cooling rates there is an increase in yield strength for the high niobium 718 while the low niobium 718 is relatively independent of cooling rates.

The grain size in these forgings were typically ASTM 7-9. A fine distribution of delta particles was observed in the microstructure as seen in Figure 16. The macrostructure of the forgings showed a uniform structure with no evidence of any significant segregation.

The tensile properties of production forgings are summarized in Figure 17. The bore properties are somewhat lower than the rim properties but the differences are small. 


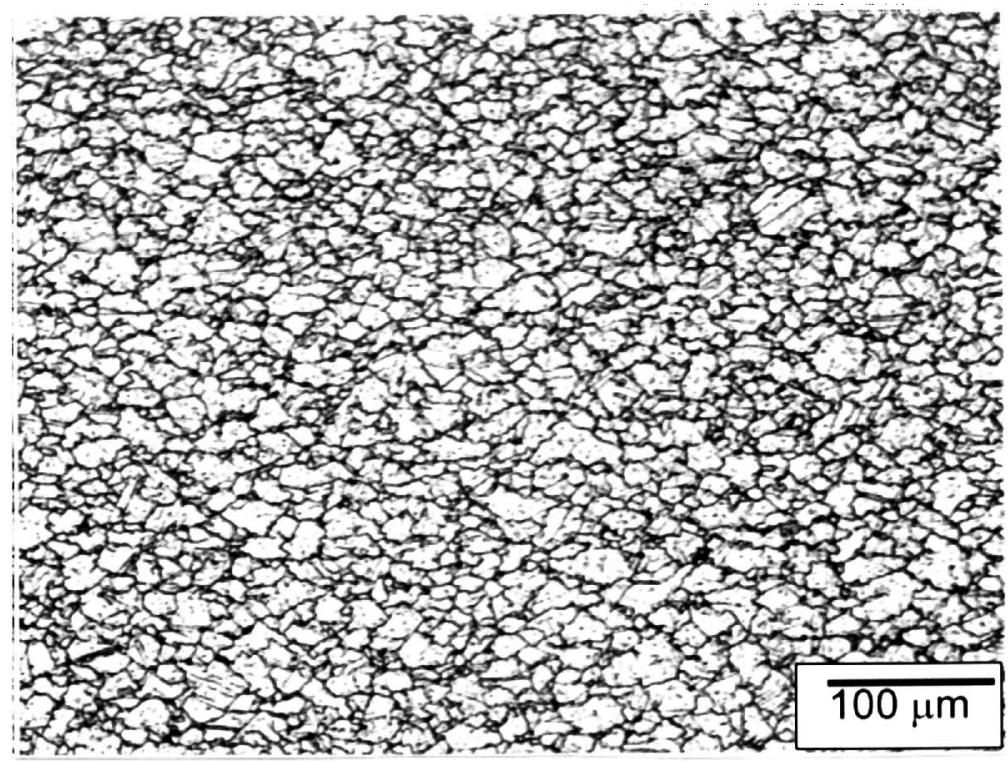

Figure 16. Microstructure of finish forged large diameter 718 forging.
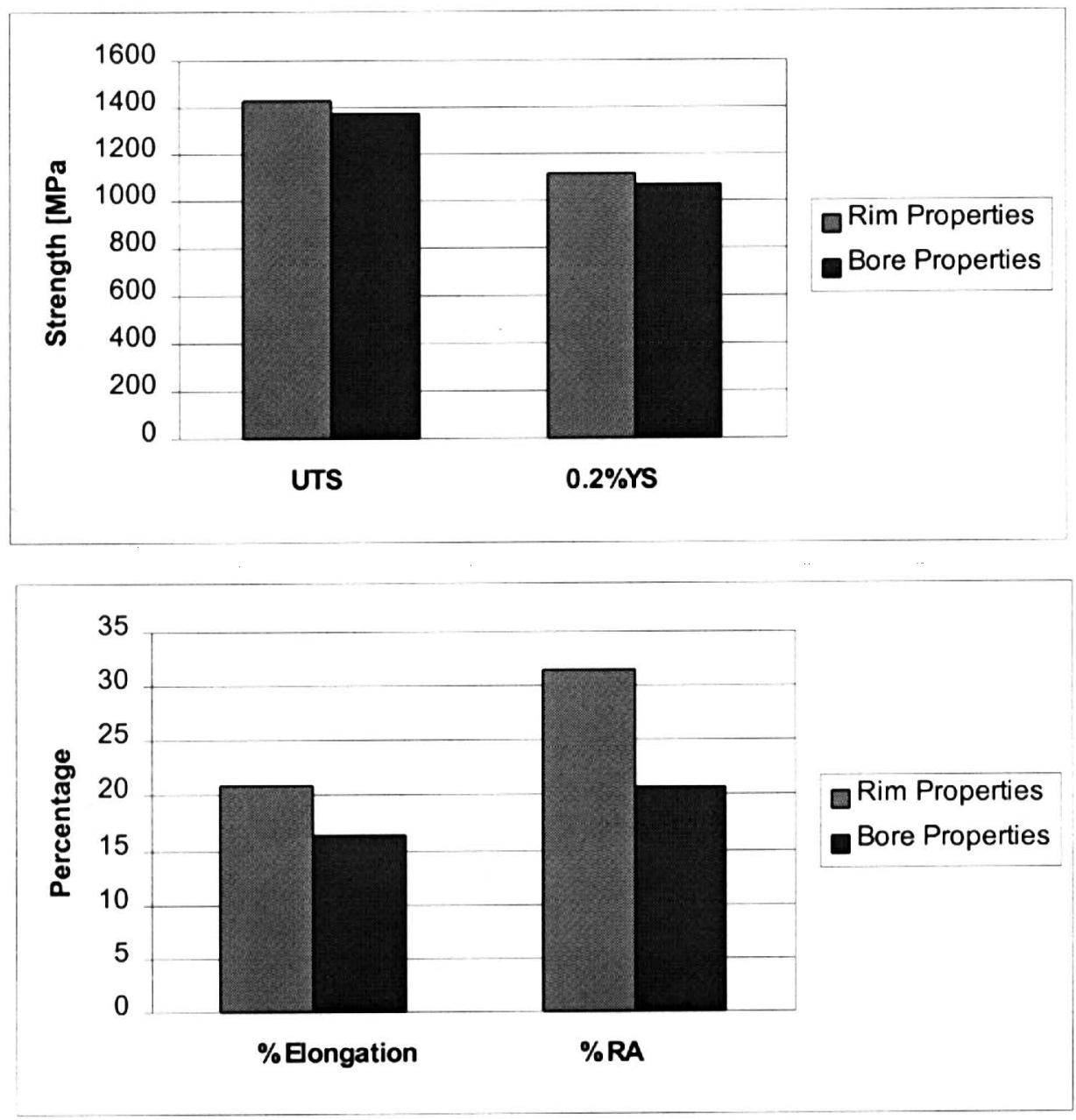

Figure 17. Percentage elongation and reduction-in-area in production forgings. 


\section{Conclusions}

Significant challenges were encountered during the development of melt processes for large 718 ingots. These have been successfully met and high quality disk forgings up to $2000 \mathrm{~mm}$ in diameter are being produced from $685 \mathrm{~mm}$ diameter ingots. These disks have fine grain structures with excellent ultrasonic penetration and exhibit mechanical properties similar to smaller disks made from smaller diameter ingots. Results from ingots $760 \mathrm{~mm}$ in diameter also are promising. However, the latest turbine designs require larger disks and therefore, larger diameter ingots of alloy 718. To meet this requirement, ingots $915 \mathrm{~mm}$ in diameter have been successfully produced without freckle-type segregation. These are now being made into disks for evaluation.

\section{References}

1. P. W. Schilke et al. "Alloy 706 Metallurgy and Turbine Wheel Application", Superalloys 718, 625, 706 and Derivatives, 1994, p 1-12.

2. A. Mitchell, "The Present Status of Melting Technology for Alloy 718", Superalloys 718.

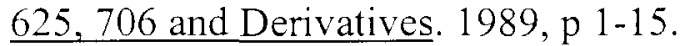

3. R. L. Kennedy, A. S. Ballantyne, B. J. Bond and L. A. Jackman, "Large Diameter Superalloy Ingots," Advanced Technologies for Superalloy Affordability, ed. K-M Chang, S. K. Srivastava, D. U. Furrer, and K. R. Bain, (The Minerals, Metals \& Materials Soc., 2000), 159171.

4. M. Cieslak et al., "The Solidification Metallurgy of Alloy 718 and Other Nb-Containing Superalloys". Superalloy 718 Metallurgy and Applications, ed. E. A. Loria, TMS, 1989, 59-68.

5. C. Ruiz et al., "Creep Behavior of Fine Grain, Low Carbon Allvac 718", Superalloys 718 , 625, 706 and Various Derivatives, ed. E. A. Loria, TMS, 1994, 523-534.

6. J. M. Moyer, "Extra Low Carbon Alloy 718", Superalloys 1984, ed. M. Gell et al., (Warrendale, PA: The Metallurgical Society, 1984), 443-454.

7. R.C. Schwant et al., "Large 718 Forgings for Land Based Turbines", Superalloys 718, 625 , 706 and Derivatives, $1997, \mathrm{p} 141-152$.

8. L. A. Jackman, G. E. Maurer, and S. Widge, "New Knowledge About White Spots in Superalloys", Advanced Materials \& Processes, 5 (1993), 18-25. 